\title{
Optimize nutritional intakes when struggling against barriers' to quality nutritional intakes
}

\section{Opinion}

I have worked with the aging population for the past 26years. A common theme that I have helped people with is how to maintain adequate energy intakes and maintain intakes of quality protein. As the population ages, it becomes more important to maintain healthy nutritional intakes, as the ability to do so decreases. Over time appetite may decrease due to disease processes or prescribed medications. Ability to chew quality protein sources may decrease as dental status deteriorates. Economic and financial factors also become important in being able to afford adequate and nutritional food choices.

My philosophy to solving many of these issues is summed up with this phrase, "less is more." Yes, less money, less chewing and less volume of oral intake is needed with this simple solution. Some of the tastiest and comforting foods that come to our minds can be transformed into calorie and protein packed foods by the simple addition of powdered nonfat dry milk. Soups, mashed potatoes, hot cereals and shakes/smoothies can have nonfat dry milk mixed easily into them. All of these items are very cost effective and are easy to eat. They become even more rich and luxurious with this addition. The best news of all is that for each $1 / 3$ cup of nonfat dry milk used; your food is fortified with approximately 120 calories and 12 grams of protein.

\author{
Volume 2 Issue 4 - 2015
}

Kathryn Oliver

Dietetic Technician, Livingston Hills Nursing and Rehabilitation

Center, USA

\begin{abstract}
Correspondence: Kathryn Oliver, Dietetic Technician, Livingston Hills Nursing and Rehabilitation Center, 294 Ostrander Road Delanson, NY I2053, New York, USA, Tel 5184210738,Email kitkat103106@yahoo.com
\end{abstract}

Received: May II, 2015 | Published: May 26, 2015

These items are more tasty, comforting and much more cost effective than any of the commercial medical nutritional supplements that can be found at your local pharmacy or grocery store.

\section{Acknowledgements}

None.

\section{Conflict of interest}

The author declares no conflict of interest. 